\title{
Decreased expression of zinc-alpha2-glycoprotein in hepatocellular carcinoma associates with poor prognosis
}

Yan Huang ${ }^{\dagger}$, Lin-Zi Li ${ }^{\dagger}$, Chris Zhi-Yi Zhang, Chun Yi, Li-Li Liu, Xuan Zhou, Guo-Bing Xie, Mu-Yan Cai, Yan Li and Jing-Ping Yun ${ }^{*}$

\begin{abstract}
Background: Zinc-alpha2-glycoprotein (AZGP1, ZAG) was recently demonstrated to be an important factor in tumor carcinogenesis. However, AZGP1 expression in hepatocellular carcinoma (HCC) and its significance remain largely unknown.

Methods: Quantitative real-time polymerase chain reaction ( $q R T-P C R$ ) was applied to determine mRNA level of AZGP1 in 20 paired fresh HCC tissues. Clinical and pathological data of 246 HCC patients were collected.

Tissue-microarray-based immunohistochemistry (IHC) was performed to examine AZGP1 expression in HCC samples. Relationship between AZGP1 expression and clinicopathological features was analyzed by Chi-square test, Kaplan-Meier analysis and Cox proportional hazards regression model.

Results: AZGP1 expression was significantly lower in $80.0 \%$ (16/20) of tumorous tissues than that in the corresponding adjacent nontumorous liver tissues $(P<0.001)$. Consistently, IHC data revealed that decreased expression of AZGP1 was present in 80.1\% (197/246) of HCC patient tissues $(P<0.001)$. Furthermore, AZGP1 expression in HCC significantly associated with several clinicopathological parameters, including serum AFP level $(P=0.013)$, liver cirrhosis $(P=0.002)$ and tumor differentiation $(P=0.025)$. Moreover, HCC patients with high AZGP1 expression survived longer, with better overall survival $(P=0.006)$ and disease-free survival $(P=0.025)$. In addition, low AZGP1 expression associated with worse relapse-free survival $(P=0.046)$ and distant metastatic progression-free survival $(P=0.036)$.
\end{abstract}

Conclusion: AZGP1 was downregulated in HCC and could be served as a promising prognostic marker for HCC patients.

Keywords: AZGP1, Hepatocellular carcinoma, Prognosis, Recurrence, Metastasis

\section{Background}

Hepatocellular carcinoma (HCC), one of the most popular tumors in the whole world, is the third leading cause of tumor mortality [1]. The incidence of HCC varies greatly around the world, with the highest prevalence in Southeast Asia and Africa. About 230,000 people (53\% of the world cases) in China die from HCC every year

\footnotetext{
* Correspondence: yunjp@sysucc.org.cn

${ }^{\dagger}$ Equal contributors

Department of Pathology, State Key Laboratory of Oncology in South China, Sun Yat-Sen University Cancer Center, Guangzhou, China, Sun Yat-Sen University Cancer Center, No 651, East Dongfeng Road, Guangzhou 510060, China
}

\section{Biomed Central}

(C) 2012 Huang et al.; licensee BioMed Central Ltd. This is an Open Access article distributed under the terms of the Creative Commons Attribution License (http://creativecommons.org/licenses/by/2.0), which permits unrestricted use, distribution, and reproduction in any medium, provided the original work is properly cited.
[2]. Hepatocarcinogenesis is a complex process and the occurrence is the result of coactions of multi-factors, such as physical condition, aflatoxin, hepatitis virus infection, cirrhosis, genetic susceptibility and epigenetic changes [3,4]. The main effective treatments of HCC include surgery, radiofrequency, combination of chemotherapeutics and radiotherapy recently, whereas post-treatment relapse and metastasis are dangerous factors of therapeutic effect $[5,6]$. Although the development of multidisciplinary treatment brings us so many advantages and disadvantages, it is urgent and necessary to identify specific markers which could predict recurrence, metastasis and prognosis for patients with $\mathrm{HCC}$ 
to improve the individual treatment. Some crucial genes are been raised to assist tumor treatment, such as BRAF and PIK3CA [7].

Zinc-alpha2-glycoprotein (AZGP1), a 40-kDa singlechain polypeptide assigned to the chromosome $7 \mathrm{q} 22.1$, is involved in carcinogenesis and differentiation. The structure and sequence of AZGP1 are highly homology to major histocompatibility complex class I (MHC I) family which may function importantly in immunity [8]. AZGP1 is a member of macroglobulin family, which is actively involved in both inhibition of tumor growth and proliferation [9]. AZGP1 was reported to inhibit the enzyme-mediated tumor invasion and activate apoptosis though binding hydrolases [10]. AZGP1 normally distributed in human liver, prostate, breast,esophagus and other organs [11]. AZGP1 has been reported to inhibit the proliferation of tumor cells by down-regulating cdc2 so as to lead to a cell cycle arrest in G2/M phase [12]. Besides, the capacity of AZGP1 to inhibit TGF$\beta$-mediated epithelial-to-mesenchymal transdifferentiation (EMT) makes it possible to inhibit tumor invasion [13]. Apart from the above-mentioned function, there is mounting evidence to show AZGP1 may play a part in the expression of the immune response [8]. As the structure and sequence are highly homology to MHC class I, AZGP1 may afford some protective effect in tumor patients and benefit to prevent the cancer progression [14].

Recent studies indicated that AZGP1 was differently expressed in human tumors. For example, its expression is increased in breast cancer, prostate cancer and lung adenocarcinoma [14-16], but decreased in pancreatic carcinoma and oral tumors [13,17]. Interestingly, expressions of AZGP1 in cancer tissues have been demonstrated to be connected with recurrence and metastasis $[18,19]$.

However, the expression of AZGP1 in HCC and its significance is still unknown. In this study, we examined the mRNA and protein levels of AZGP1 in HCC and determined the relationship between AZGP1 expression and various clinicopathologic parameters in order to systematically investigate whether AZGP1 plays a role in HCC carcinogenesis and its clinical significance.

\section{Materials and methods}

\section{Patients and tissue specimens}

Paraffin-embedded specimens from 246 patients with HCC between 1997 and 2001 by immunohistochemistry, as well as clinical and pathological data, and 20 cases of resected fresh tissues with HCC between Jan and Jul 2011 for analysis of mRNA and protein expression, were collected from Sun Yat-Sen University Cancer Center, Guangzhou, China. The 246 cases, with histologically conformed were randomly selected from 400 patients with
HCC who underwent initial surgical resection and did not receive preoperative radiotherapy or chemotherapy. Child-Pugh classification and the 15-min retention rate for indocyanine green (ICGR15) were essential to be considered in the preoperative assessment. The cases selected were based on availability of 10 years' follow-up data and complete medical records. Patients whose cause of death remain unknown were excluded form our study. The 246 cases aged from 14 to 78 years (mean, 48 years) include 219 males (91.3\%) and 27 females (8.7\%). Clinicopathologic characteristics for these patients were described in Table 1. Tumor differentiation was assessed according to the criteria proposed by Edmonson and Steiner [20]. Tumor stage was defined according to American Joint Committee on Cancer/International Union Against Cancer tumor-node-metastasis (TNM) classification system [21]. The use of tissues for this study was approved by the Institute Research Medical Ethics Committee of Sun Yat-Sen University Cancer Center and written informed consent was obtained from each patient.

\section{RNA preparation and quantitative real-time polymerase chain reaction}

Total RNA was extracted from 20 pairs of HCC tissues and the adjacent non-tumorous liver tissues from 20 cases of fresh tissues with HCC using Trizol regent (BIOO Scientific Corp., Austin, TX,USA) and cDNA was synthesised using SuperScript RT kit (Promega, Madison, WI, USA) according to the manufacturer's instructions. The expression levels of AZGP1 and $\beta$ actin were measured using SYBR green-based real-time PCR performed on the Stratagene Mx3000P Real-Time PCR system. The primer sequences for AZGP1 were sense, ACGACAGTAACGGGTCTCAC and antisense, AGGCTGGGATTTCTTTGTTGAA, whereas those for $\beta$-actin were sense, TGGCACCCAGCACAATGAA and antisense CTAAGTCATAGTCCGCCTAGAAGCA. The optimised amplification protocol consisted of an initial denaturation step of $95^{\circ} \mathrm{C}$ for $10 \mathrm{~min}$, followed by 40 amplification cycles at $95^{\circ} \mathrm{C}$ for $10 \mathrm{~s}$, annealing at $59^{\circ} \mathrm{C}$ for $20 \mathrm{~s}$ and elongation at $72^{\circ} \mathrm{C}$ for $10 \mathrm{~s}$. The foldchanges for AZGP1 expression levels were calculated using $2-\Delta \Delta \mathrm{Ct}$.

\section{Western blot}

The 20 pairs of fresh samples including tumor tissues and the adjacent non-tumorous liver tissues were homogenated in a RIPA lysis buffer, and lysates were cleared by centrifugation $(12,000 \mathrm{rpm})$ at $4^{\circ} \mathrm{C}$ for $30 \mathrm{~min}$. The supernatant was collected and total protein $(50 \mu \mathrm{g})$ was separated on $12 \%$ SDS-polyacrylamide gel electrophoresis (PAGE), and electrotransferred on a polyvinylidene difluoride (PVDF) membrane (Pall Corp., Port Washington, NY). After blocking non-specific 
Table 1 Correlation between AZGP1 expression and clinical and pathological characters in HCC

\begin{tabular}{|c|c|c|c|c|c|}
\hline \multirow[t]{2}{*}{ Variable } & \multicolumn{5}{|c|}{ AZGP1 protein } \\
\hline & All cases & Low expression & High expression & $x^{2}$ & $P_{\text {value }}^{a}$ \\
\hline Age(years) b & & & & 0.134 & 0.714 \\
\hline 48 & 119 & $46(38.7)$ & $73(61.3)$ & & \\
\hline$\geq 48$ & 127 & $52(40.9)$ & $75(59.1)$ & & \\
\hline \multicolumn{6}{|l|}{ Mean $\pm S D(47.9 \pm 11.8)$} \\
\hline Gender & & & & 0.099 & 0.753 \\
\hline Female & 27 & $10(37.0)$ & $17(63.0)$ & & \\
\hline Male & 219 & $88(40.2)$ & 131(59.8) & & \\
\hline $\mathrm{HBsAg}$ & & & & 0.673 & 0.412 \\
\hline Yes & 213 & $87(40.8)$ & $126(59.2)$ & & \\
\hline No & 33 & $11(33.3)$ & $22(66.7)$ & & \\
\hline $\operatorname{AFP}(n g / m l)$ & & & & 6.182 & 0.013 \\
\hline$\leq 20$ & 104 & $32(30.8)$ & $72(69.2)$ & & \\
\hline$>20$ & 142 & $66(46.5)$ & $76(53.5)$ & & \\
\hline Liver cirrhosis & & & & 9.244 & 0.002 \\
\hline Yes & 177 & $81(45.8)$ & $96(54.2)$ & & \\
\hline No & 69 & $17(24.6)$ & $52(75.4)$ & & \\
\hline Tumor size (cm) & & & & 0.457 & 0.499 \\
\hline$\leq 5$ & 127 & $48(37.8)$ & $79(62.2)$ & & \\
\hline$>5$ & 119 & $50(42.0)$ & $69(58.0)$ & & \\
\hline Tumor multiplicity & & & & 0.042 & 0.837 \\
\hline Single & 130 & $51(39.2)$ & 79 (60.8) & & \\
\hline Multiple & 116 & $47(40.5)$ & $69(59.5)$ & & \\
\hline Tumor differentiation & & & & 9.347 & 0.025 \\
\hline Well (I) & 33 & $6(18.2)$ & $27(81.8)$ & & \\
\hline Moderate (II) & 125 & $54(43.2)$ & $71(56.8)$ & & \\
\hline Poor (III) & 76 & $35(46.1)$ & $41(53.9)$ & & \\
\hline Undifferentiation (IV) & 12 & $3(25)$ & $9(75)$ & & \\
\hline Clinical Stage & & & & 2.154 & 0.541 \\
\hline 1 & 16 & $5(31.3)$ & $11(68.7)$ & & \\
\hline$\|$ & 93 & $33(35.5)$ & $60(61.5)$ & & \\
\hline III & 106 & $46(43.4)$ & $60(56.6)$ & & \\
\hline IV & 31 & $14(45.2)$ & $17(54.8)$ & & \\
\hline Vascular invasion & & & & 1.966 & 0.161 \\
\hline Yes & 73 & $34(46.6)$ & $39(53.4)$ & & \\
\hline No & 173 & $64(37.0)$ & $109(63.0)$ & & \\
\hline
\end{tabular}

${ }^{a}$ Chi-square test; $b$ patients were divided according to the median age; $A F P$, alpha-fetoprotein; $H B s A g$, hepatitis $B$ surface antigen; $A Z G P 1$, zinc-alpha2-glycoprotein.

binding sites for $1 \mathrm{~h}$ with $5 \%$ non-fat milk, the membranes were then incubated with primary mouse monoclonal antibodies against AZGP1 (Santa Cruz Biotechonlogy, CA, USA, at 1:1000 dilution), and GAPDH (Santa Cruz Biotechonlogy, CA, USA, at 1:4000 dilution) at $4^{\circ} \mathrm{C}$ overnight. After washing, the membrane was then incubated with the secondary anti-mouse antibody (Santa Cruz Biotechnology, CA, USA) for $1 \mathrm{~h}$ at room temperature. The immunoreactive signals were detected with enhanced chemiluminescence kit (Amersham Biosciences, Uppsala,
Sweden). The procedures followed were conducted in accordance with the manufacturer's instructions.

\section{Tissue microarray (TMA)}

Tissue microarray was constructed according to the method described previously [22]. Briefly, all samples were fixed in formalin and embedded in paraffin. The corresponding histological hematoxylin and eosin (H\&E)-stained sections were reviewed by two pathologists to determine and mark out representative areas of 
the paraffin blocks. Each case had four core biopsies, which contained two tumor tissues and two adjacent non-tumorous liver tissues. Each tissue core with a diameter of $0.6 \mathrm{~mm}$ was punched from the marked areas and re-embedded into a recipient paraffin arrayblock. Multiple sections (3- $\mu \mathrm{m}$ thick) were cut and mounted on microscope slides. After then, one section from the tissue array block was stained with H\&E and confirmed that the punches had got the representative areas.

\section{Immunohistochemistry}

Immunohistochemical detection for AZGP1 was performed using a standard two-step method. The TMA sections were dried overnight at $37^{\circ} \mathrm{C}$, deparaffinized in xylene and hydrated through a series of graded alcohol. Before antigen retrieval, endogenous peroxidase activity was inhibited with $3 \%$ hydrogen peroxide for $20 \mathrm{~min}$. Then the slides were boiled in ethylene diamine tetraacetic acid (EDTA; $1 \mathrm{mmol} / \mathrm{L} ; \mathrm{PH} 8.0$ ) by a pressure cooker for $5 \mathrm{~min}$. After washing five times in phosphate buffered saline (PBS; $0.01 \mathrm{~mol} / \mathrm{L} ; \mathrm{pH}=7.4$ ), the slides were preincubated with $10 \%$ normal goat serum for $30 \mathrm{~min}$ to reduce nonspecific antibody binding. Subsequently, they were incubated overnight at $4^{\circ} \mathrm{C}$ with the rabbit polyclonal antibody against AZGP1 (Protein Tech Group, Chicago, IL, USA; 1:800 dilution). After rinsing, the slides were incubated with a secondary antibody (Dako Corp., Glostrup, Denmark) for $1 \mathrm{~h}$ at room temperature, and stained with 3, 3-diaminobenzidine tetrahydrochloride $(\mathrm{DAB})$ after washing in PBS again. Finally, they were counterstained with Mayer's hematoxylin, dehydrated, and mounted. Slides were immunoreacted with PBS as the negative controls. Known immunostaining-positive slides were used as positive controls.

\section{Immunohistochemistry evaluation}

Semi-quantitative immunohistochemical detection was used to determine the AZGP1 protein levels. Cytoplasm immunoreactivity for the AZGP1 protein was scored by evaluating the sum of positive tumor cells and the staining intensity over the total number of tumor cells. In brief, the percent of positive cells was scored as "0" (0\%), "1" (1\%-10\%), "2" (11\%-50\%), "3" (51\%-80\%), "4" (81\%$100 \%)$. Intensity was scored as "0" (no staining), "1" (weakly stained), "2" (moderately stained), and "3" (strongly stained). Both the scores were decided under double-blind conditions by three independent professionals. The final immunoreactive scores were determined by multiplying the intensity scores with the extent of positivity scores of stained cells $[23,24]$. The scores were then classified as follow: "-" (score 0), "+" (score 1-4), "++" (score 5-8), and "+++"' (score 9-12). For the purpose of statistical analysis, the cohort was grouped into low expression group ("-"," + ") and high expression group ("++","+++") for either 246 tumor tissues or their adjacent non-tumorous liver tissues.

\section{Statistical analysis}

Statistical analyses were performed with the SPSS 13.0 software (SPSS, Chicago, IL, USA). The correlation between AZGP1 expression and various clinical and pathological characteristics were evaluated by Paired sample $t$ test. Kaplan-Meier analyses were used to analyze AZGP1 as univariate in prediction of patients' survival. Comparisons of survival distributions were done with log-rank test. The multivariate survival analyses were performed by a stepwise Cox proportional hazard model using the Wald statistics. $P$ values of $<0.05$ were considered significant.

\section{Results}

The expression of AZGP1 in HCC by qRT-PCR and western blotting

Results showed that in 16 out of 20 cases, AZGP1 mRNA expressions in HCC tissues were noticeably lower than those in the adjacent non-tumorous liver tissues, as determined by qRT-PCR. As depicted in Figure 1A, mRNA level of AZGP1 in HCC tissue was on average 15.5-fold lower than that in corresponding adjacent liver tissue. There was significant difference in the average level of AZGP1 between tumor tissues and non-tumorous tissues $(P=0.001)$. To examine the protein level of AZGP1 in HCC, western blot was performed (Figure 1B). The ratio of AZGP1 expression in non-tumorous tissues to that in tumorous tissues was calculated. Results showed that AZGP1 expression in tumorous tissues was on average 1.55-fold lower than that in the paired non-tumorous tissues.

\section{The expression of AZGP1 in HCC by immunohistochemistry}

The protein status of AZGP1 was further examined by TMA and IHC, using 246 pairs of HCC and adjacent non-tumorous liver tissues (Figure 2). Results indicated that reduced expression of AZGP1 presented in $80.1 \%$ of HCC tissues (Figure 2A C). Kruskal-Wallis's analysis revealed that AZGP1 expression was significantly decreased by more than 2-fold in tumorous tissues, compared to that in adjacent non-tumorous liver tissues $(P<0.001, t=-6.502)$ (Figure 2D).

\section{The relationship between AZGP1 expression and clinicopathological parameters}

To investigate the relationship between AZGP1 expression and clinicopathological parameters in 246 cases with HCC, these cases were first divided into two subgroups: "Low AZGP1 expression" and "High AZGP1 expression" as defined in the Immunohistochemistry 

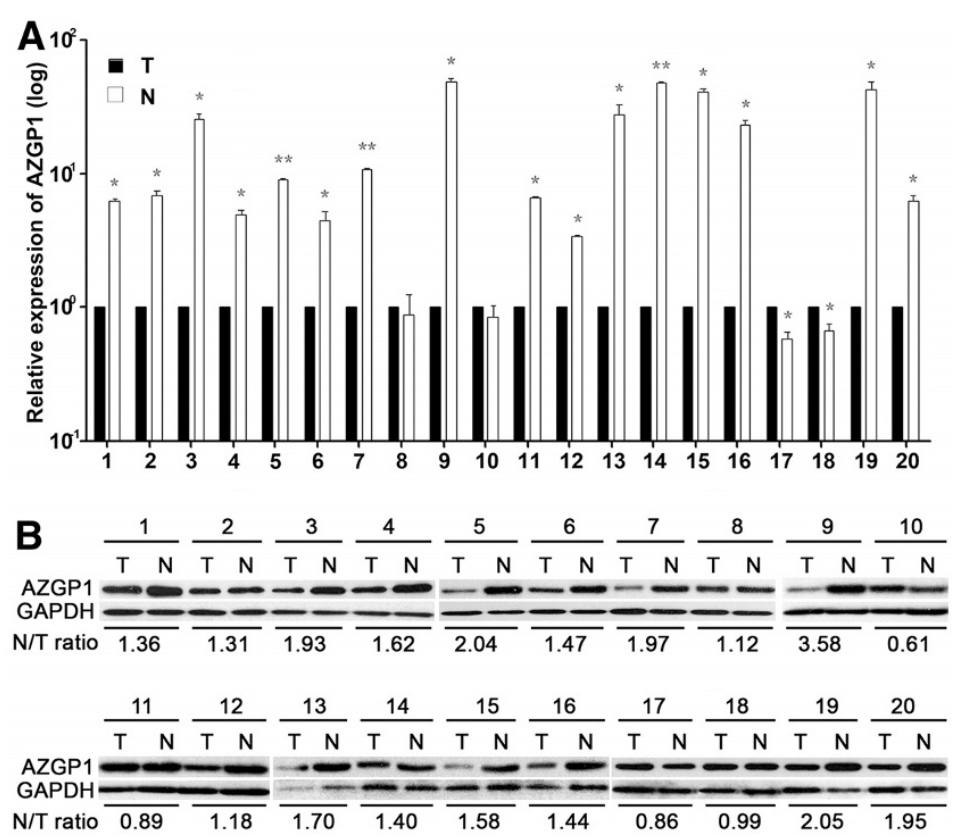

Figure 1 The expression of AZGP1 in HCC by qRT-PCR and Western blotting. A. Expression of AZGP1 mRNA in HCC tissues (T) and the adjacent non-tumorous liver tissues $(\mathrm{N})(\mathrm{n}=20)$ was examined by qRT-PCR. Data were mean \pm SD of three independent experiments. ${ }^{*}, P<0.05$ and ${ }^{*}, P<0.001$ versus to the adjacent non-tumorous liver tissues. B. Expression of AZGP1 protein in HCC tissues ( $T$ ) and the adjacent nontumorous liver tissues $(N)(n=20)$ was examined by Westen blotting. Ratio of AZGP1 expression in $N$ to T was indicated.

section of Materials and Methods. Significant correlations were found between AZGP1 expression and three parameters including serum AFP levels $(P=0.013)$, cirrhosis $(P=0.002)$ and tumor differentiation $(P=0.017)$. Patients with low AZGP1 expression had a higher tendency to have high level of serum AFP, liver cirrhosis, and poor tumor differentiation. There were no statistical connections between AZGP1 expression and the rest clinicopathological parameters, such as patient age, gender, HBsAg, tumor size, tumor multiplicity, clinical stage and vascular invasion $(P>0.05$, Table 1$)$.

\section{The association of low AZGP1 expression in HCC with poor survival in patient}

The association between AZGP1 expression in HCC and the survival time of selected patients was analyzed with Kaplan-Meier survival analysis (Figure 3). The median overall survival (OS) time of low AZGP1
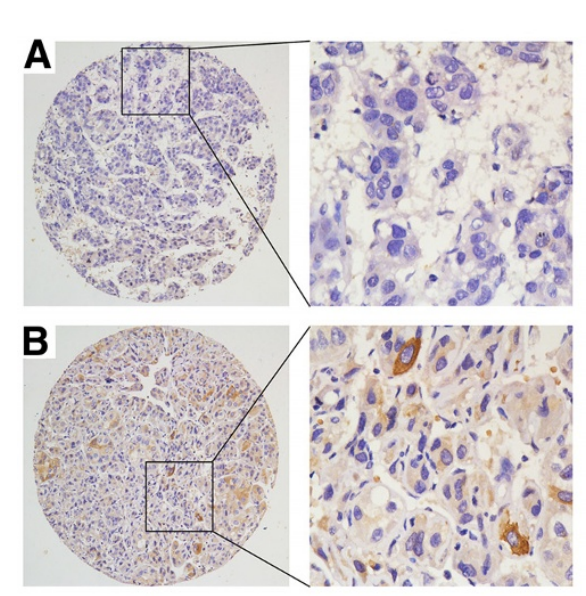

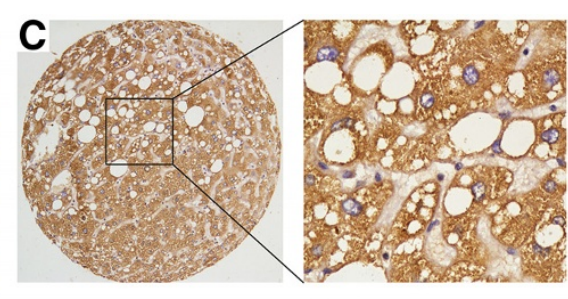

D

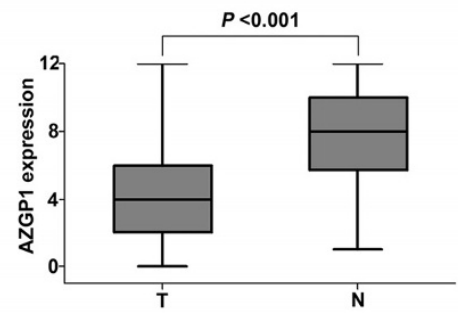

Figure 2 The protein expression of AZGP1 in HCC by immunohistochemistry. The immunoreactivity was primarily observed in the cytoplasm within tumor cells. A. Negative staining of AZGP1 was detected in HCC case (\#136) B. HCC case (\#57) showed weak expression of AZGP1. C. Strong staining of AZGP1 was observed in 95\% of the adjacent non-tumorous liver tissues. D. The box plot showed the mean staining score of AZGP1 in HCC tissues ( $T$ ) and the adjacent non-tumorous liver tissues $(N)(P<0.001, t=-6.502)$. 

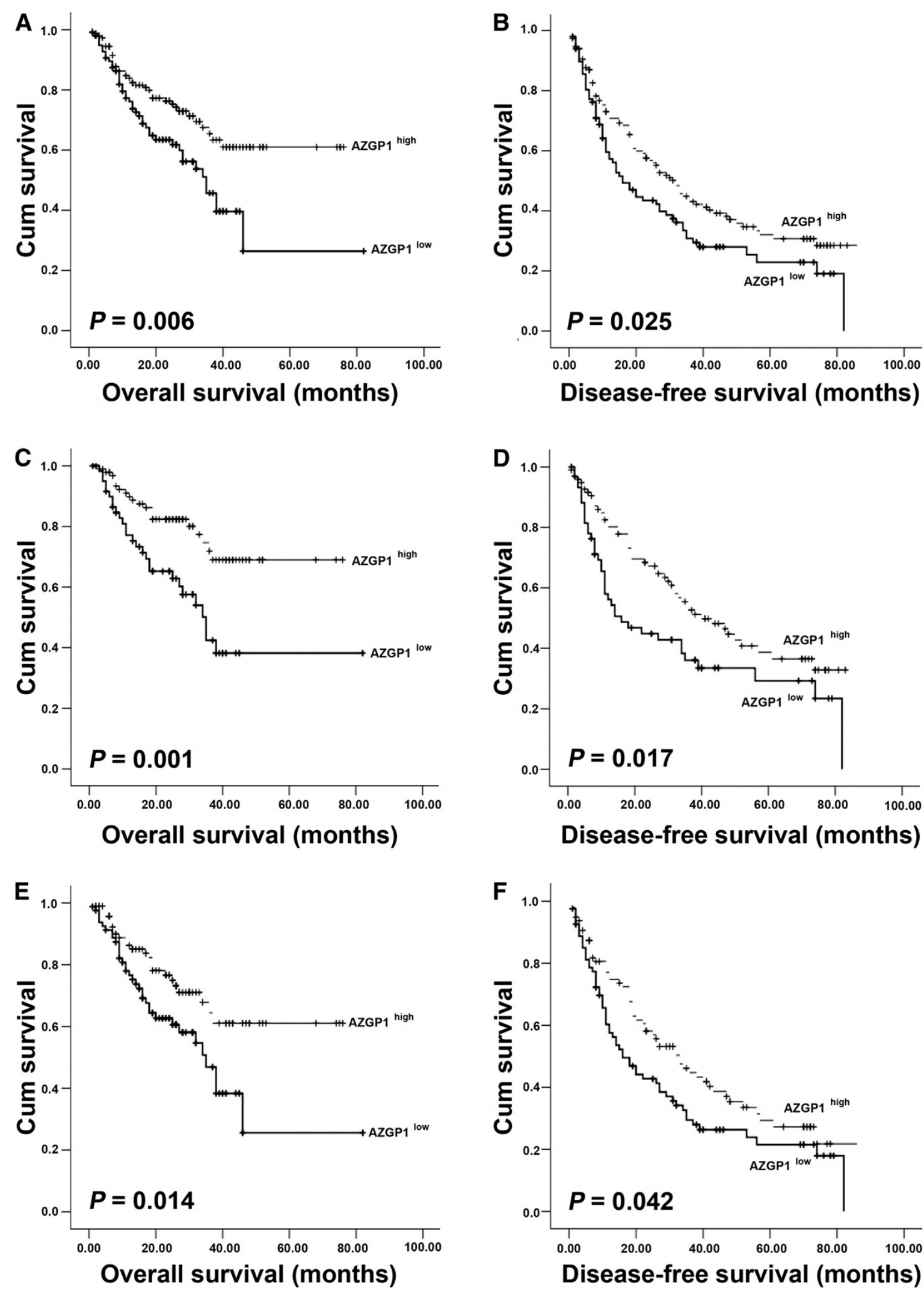

Figure $\mathbf{3}$ (See legend on next page.) 
(See figure on previous page)

Figure 3 Survival analysis of AZGP1 expression in HCC. A, B. Probability of OS (A) and DFS (B) of total HCC patients. C, D. Probability of OS (C) and DFS (D) of well differentiated (grade I+II) HCC patients. E, F. Probability of OS (E) and DFS (F) of positive cirrhosis HCC patients.

expression group was 34.1 months, significantly shorter than that of high AZGP1 expression group (72 months) $(P=0.006$, Figure 3A). Furthermore, the median disease-free survival (DFS) time of low AZGP1 expression group was remarkably shorter than that of high AZGP1 expression group ( $P=0.025$, Figure 3B). Statistically, the 5-year OS rate and DFS rate of low AZGP1 expression group were $31.0 \%$ and $22.5 \%$, respectively, whereas they were $44.8 \%$ and $32.0 \%$, respectively, in high AZGP1 expression group. Moreover, we stratifiedly analyzed the subtype of patient with well tumor differentiation (OS: $P=0.001$, Figure 3C; DFS: $P=0.017$, Figure 3D) and liver cirrhosis (OS: $P=0.014$, Figure 3E; DFS: $P=0.042$, Figure 3F). Results showed that HCC patients with high AZGP1 expression survived longer.

Univariate analysis was also performed on 11 clinialpathological parameters that may affect postoperative survival of HCC patients (Table 2). Results indicated that AZGP1 expression, as well as serum AFP level, tumor size, tumor multiplicity, tumor differentiation, clinical stage and vascular invasion, was one of the factors that are responsible for efficacy of surgical treatment in HCC patient, by showing that AZGP1 expression was significantly correlated to OS $(P=0.007)$ and DFS $(P=0.033)$ of HCC patients. Next, we subjected the statistically significant parameters to Cox proportional hazards regression model to evaluate the significance of AZGP1 expression in HCC prognosis. Results suggested AZGP1 expression was not an effective independent prognostic factor (Table 3).
Association of high AZGP1 expression with long period of recurrence and distant metastasis

We further assessed whether AZGP1 expression in HCC was related to the risk of recurrence and metastasis. Survival analysis indicated that AZGP1 expression was negatively associated with the risk of clinical recurrence ( $\mathrm{HR}=0.698,95 \% \mathrm{CI}=0.488$ to $0.999, P=0.046$; Figure $4 \mathrm{~A})$ and distant metastatic progression $(\mathrm{HR}=0.679,95 \% \mathrm{CI}=$ 0.471 to $0.981, P=0.036$; Figure $4 \mathrm{~B})$. This may suggest AZGP1 may be involved in tumor recurrence and metastasis.

\section{Discussion}

Recently, it has been shown that AZGP1 plays a crucial role in carcinogenesis and is of clinicopathologic significance in human cancers $[8,25-28]$. In the present study, AZGP1 expression was found to be decreased in HCC tissues at both mRNA and protein levels. Moreover, low expression of AZGP1 was notably more prevalent in patients with poor tumor differentiation, serious liver cirrhosis, high serum AFP level and short survival time. Our results may suggest AZGP1 as a promising novel prognostic biomarker for HCC.

Recently reports showed AZGP1 was overexpressed in some tumors, but lost or reduced in other tumors $[13,17]$. Although the exact mechanism remains elusive, expression of AZGP1 is partly attributed to the acetylation status of histone which regulates gene activity by changing the conformation of chromatin. Daniel and colleagues found that AZGP1 was upregulated in lung adencarcinoma due

Table 2 Univariate analysis of different prognostic factors in 246 HCC patients

\begin{tabular}{|c|c|c|c|c|}
\hline \multirow[t]{2}{*}{ Variable } & \multicolumn{2}{|c|}{ Overall survival rate (\%) } & \multicolumn{2}{|c|}{ Disease-free survival rate (\%) } \\
\hline & HR $(95 \% \mathrm{Cl})$ & $P$ value & HR $(95 \% \mathrm{Cl})$ & $P$ value \\
\hline Age (years) & $1.037(0.674-1.596)$ & 0.867 & $1.120(0.816-1.539)$ & 0.482 \\
\hline Gender & $0.74(0.356-1.536)$ & 0.419 & $1.215(0.741-1.990)$ & 0.44 \\
\hline $\mathrm{HBsAg}$ & $0.776(0.421-1.431)$ & 0.416 & $1.140(0.697-1.865)$ & 0.601 \\
\hline AFP (ng/ml) & $3.408(2.038-5.698)$ & $<0.001$ & 2.088(1.499-2.909) & $<0.001$ \\
\hline Liver cirrhosis & $1.087(0.672-1.760)$ & 0.733 & $1.174(0.813-1.694)$ & 0.392 \\
\hline Tumor size $(\mathrm{cm})$ & $2.409(1.532-3.790)$ & $<10.001$ & $1.806(1.311-2.488)$ & $<0.001$ \\
\hline Tumor multiplicity & $3.233(2.022-5.168)$ & $<0.001$ & $1.972(1.429-2.722)$ & $<0.001$ \\
\hline Tumor differentiation & $1.649(1.246-2.183)$ & $<0.001$ & $1.621(1.314-2.000)$ & $<0.001$ \\
\hline Clinical stage & $3.079(2.269-4.178)$ & $<0.001$ & $1.785(1.457-2.187)$ & $<0.001$ \\
\hline Vascular invasion & 4.704(3.027-7.311) & $<0.001$ & 2.393(1.714-3.341) & $<0.001$ \\
\hline AZGP1 & $0.553(0.359-0.851)$ & 0.007 & $0.706(0.513-0.972)$ & 0.033 \\
\hline
\end{tabular}

$C l$, confidence interval; $H R$, hazard ratio; $A F P$, alpha-fetoprotein; $H B s A g$, hepatitis B surface antigen; $A Z G P 1$, zinc-alpha2-glycoprotein. 
Table 3 Multivariate analysis of overall and disease-free survival rates of HCC patients

\begin{tabular}{|c|c|c|c|c|}
\hline Variable & $\beta$ & SE & Hazard ratio $(95 \% \mathrm{Cl})$ & $P$ value \\
\hline \multicolumn{5}{|l|}{ Overall sruvival } \\
\hline Clinical stage & 1.382 & 0.468 & $3.982(1.590-9.974)$ & 0.003 \\
\hline Vascular invasion & 0.895 & 0.258 & $2.448(1.477-4.059)$ & 0.001 \\
\hline AFP & 0.781 & 0.273 & $2.184(1.279-3.730)$ & 0.004 \\
\hline Tumor differentiation & 0.599 & 0.299 & $0.550(0.306-0.988)$ & 0.045 \\
\hline Tumor multiplicity & 0.438 & 0.283 & $1.549(0.889-2.698)$ & 0.122 \\
\hline AZGP1 & -0.321 & 0.231 & $0.725(0.461-1.141)$ & 0.164 \\
\hline Tumor size & 0.319 & 0.245 & $1.376(0.852-2.224)$ & 0.192 \\
\hline \multicolumn{5}{|l|}{ Disease-free survival } \\
\hline Relapse & 1.252 & 0.167 & $3.499(2.522-4.854)$ & $<0.001$ \\
\hline Vascular invasion & 0.775 & 0.206 & $2.171(1.449-3.253)$ & $<0.001$ \\
\hline AFP & 0.533 & 0.173 & $1.705(1.215-2.392)$ & 0.002 \\
\hline Tumor differentiation & 0.521 & 0.232 & $0.594(0.377-0.936)$ & 0.025 \\
\hline Tumor size & 0.361 & 0.18 & $1.435(1.009-2.041)$ & 0.044 \\
\hline Tumor multiplicity & 0.427 & 0.238 & $1.533(0.962-2.443)$ & 0.072 \\
\hline$\overline{A Z G P 1}$ & -0.211 & 0.166 & $0.810(0.585-1.121)$ & 0.204 \\
\hline Clinical stage & 0.188 & 0.286 & $1.207(0.689-2.115)$ & 0.510 \\
\hline
\end{tabular}

$\beta$, Regression coefficient; $S E$, standard error; $C l$, confidence interval; AFP, alphafetoprotein; $A Z G P 1$, zinc-alpha2-glycoprotein.

to histone acetylation [13]. Kong et al. also suggested that AZGP1 in pancreatic ductal adenocarcinoma is lost owing to histone deacetylation [14]. However, whether histone deacetylation contributes to the decreased expression of AZGP1 found in this study requires further investigation.

Reports demonstrated that poorly differentiated tumors expressed less AZGP1 than well differentiated tumors in most of popular human tumors, such as breast cancer, prostate cancer, oral squamous cell carcinomas, epidermal tumors, sweat gland tumors, pancreatic cancer and cervical cancer [13,15,16,26-30]. Interestingly, complicated relationships between AZGP1 expression and clinical stages of cancer patients are common. AZGP1 was stagedependent increased in the urinary bladder cancer [25]. However, an inverse association between AZGP1 expression with tumor stage was found in prostate cancer [29]. In addition, AZGP1 expression is correlated positively to leptin receptor and negatively to adiponectin receptor and estrogen receptor in breast cancer tissue. In our study, low level of AZGP1 appeared to be significantly associated with poorer differentiation. Although the percentage of patients with HBV infection was greater and the ages of patients were younger in our study, when compared to patients with HCC in Western countries or Japan, our findings suggest that loss or decrease expression of AZGP1 may promote HCC progression. Further studies should be needed to examine the role of AZGP1 in patients with HCV-related HCC or without hepatitis viral infection.

AZGP1 is considered as a potential biomarker of various tumors. AZGP1 was also proposed as predictor for breast cancer due to its elevated expression in cancer and normal epithelial adjacent tissues but not in normal tissue of healthy women [31]. AZGP1 was reported to be a diagnostic marker for cancer cachexia due to its high expression [32,33]. In prostate cancer, AZGP1 could be served as a potential serum maker, being expressed in malignant prostatic epithelium [16]. However, relationship between AZGP1 and HCC has not been studied. In the present study, we showed that AZGP1 expression was decreased by over 2 folds in HCC tissues, compared to that in the adjacent non-tumorous liver tissues. These
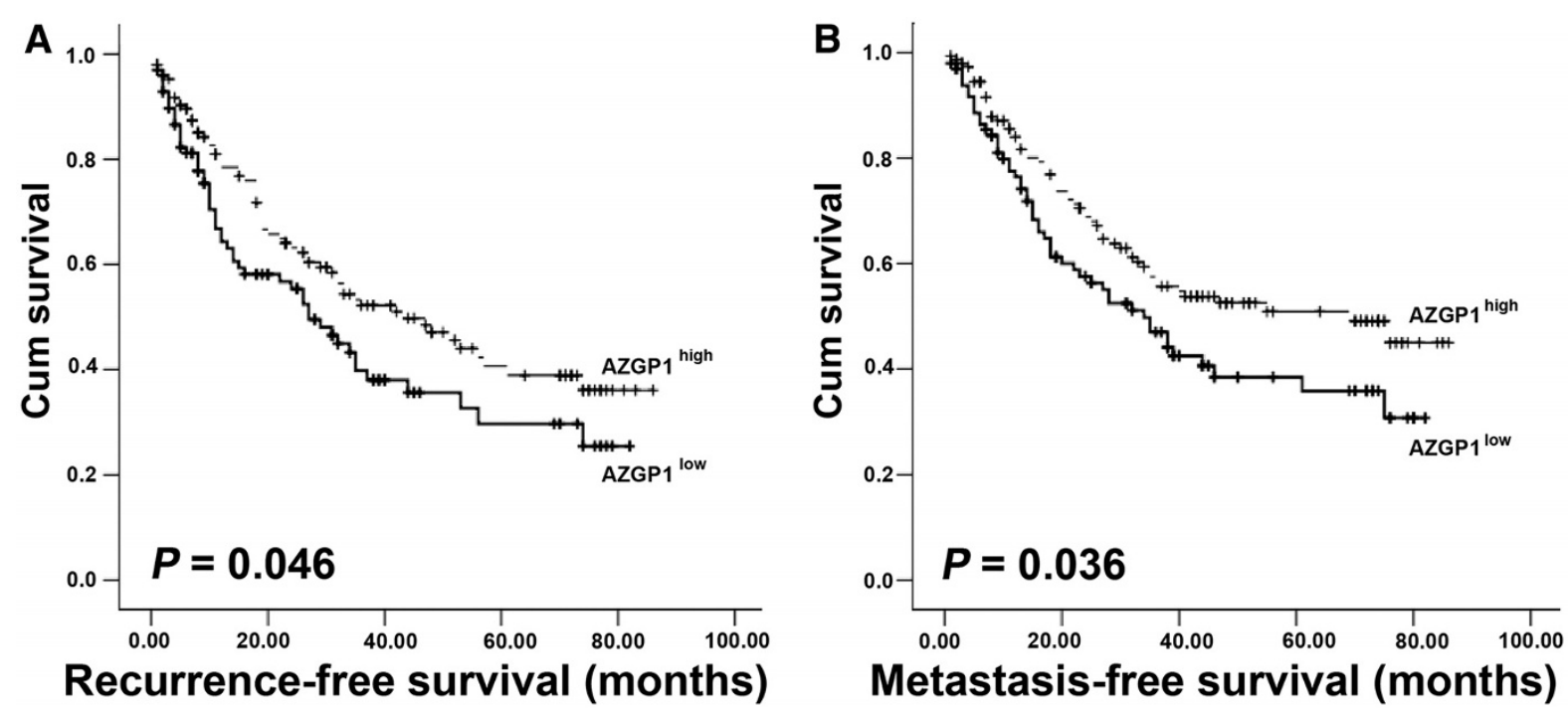

Figure 4 Association of AZGP1 with HCC patients' recurrence and metastasis. A. Recurrence-free survival in patients stratified by AZGP1 expression. B. Metastasis-free survival in patients stratified by AZGP1 expression. 
data indicated a role for AZGP1 of a potential biomarker to give a selective advantage in the HCC tumor progression.

AZGP1 has been identified as a predictor of prognosis in some tumors. In lung adenocarcinoma and prostate cancer, patients with high levels of AZGP1 had better survival than those with low levels of AZGP1 [14,29,34]. Absent or weak AZGP1 expression is reported to be associated with shorter recurrence-free and metastasisfree survival of prostate cancer patients $[18,19]$. In our study, HCC patients with low AZGP1 expression had shorter survival time. Cox regression analysis indicated that AZGP1 might be one of the factors that affect HCC patients' survival. High AZGP1 expression was associated with significantly longer period of clinical recurrence and distant metastasis. These observations suggest that it might be of significance to utilize the expression of AZGP1 as a preliminary diagnostic approach to distinguish HCC from non-tumourous liver disease, and that more attention should be paid to HCC patients with decreased AZGP1 expression during and after the process of therapy. However, it is noteworthy that further investigation and validation are required before a clinical practice. Collectively, these data suggest that AZGP1 may be a promising prognostic marker for $\mathrm{HCC}$.

\section{Conclusion}

In summary, our study demonstrated that AZGP1 was frequently decreased in HCC. Low expression of AZGP1 could be served as a tumor biomarker for poor differentiation and a predictor for poor prognosis of HCC patients.

\footnotetext{
Abbreviations

AZGP1: Zinc-alpha2-glycoprotein; HCC: Hepatocellular carcinoma; qRTPCR: Quantitative real-time polymerase chain reaction;

IHC: Immunohistochemistry; AFP: Alpha-fetoprotein; HBV: Hepatitis B virus; HCV: Hepatitis C virus; HBsAg: Hepatitis B surface antigen; MHC I: Major histocompatibility complex class I; ICGR15: The 15-min retention rate for indocyanine green; TNM: Tumor-lymph node-metastasis; TMA: Tissue microarray; OS: Overall survival; DFS: Disease-free survival.
}

\section{Competing interests}

The authors declare that they have no competing interests.

\section{Authors' contributions}

JPY carried out and coordinated the study. YH, LZL, LLL, GBX, and YL performed the experiments; YH, LZL, CY, XZ, MYC, and Chris ZYZ analyzed the data; $Y H$ wrote the paper; All authors read and approved the final manuscript.

\section{Acknowledgements}

This study was supported by grants from the National Natural Science Foundation of China (No.30973506 and 81172345). We thank Dr. Dan Xie for his critical suggestions regarding this work.

Received: 15 March 2012 Accepted: 9 May 2012

Published: 24 May 2012

\section{References}

1. Lau WY, Lai EC, Lau SH: The current role of neoadjuvant/adjuvant/ chemoprevention therapy in partial hepatectomy for hepatocellular carcinoma: a systematic review. Hepatobiliary Pancreat Dis Int 2009, 8:124-133.

2. Zheng L, Liang P, Li J, Huang XB, Wang WW, Wang L, Feng $H$ : Expression of BC047440 protein in hepatocellular carcinoma and its relationship to prognosis. Chin J Cancer 2010, 29:931-936.

3. Aravalli RN, Steer CJ, Cressman EN: Molecular mechanisms of hepatocellular carcinoma. Hepatology 2008, 48:2047-2063.

4. Marra M, Sordelli IM, Lombardi A, Lamberti M, Tarantino L, Giudice A, Stiuso P, Abbruzzese A, Sperlongano R, Accardo M, et al: Molecular targets and oxidative stress biomarkers in hepatocellular carcinoma: an overview. J Transl Med 2011, 9:171.

5. Caraglia M, Giuberti G, Marra M, Addeo R, Montella L, Murolo M, Sperlongano P, Vincenzi B, Naviglio S, Prete SD, et al: Oxidative stress and ERK1/2 phosphorylation as predictors of outcome in hepatocellular carcinoma patients treated with sorafenib plus octreotide LAR. Cell Death Dis 2011, 2:e150.

6. Frau M, Biasi F, Feo F, Pascale RM: Prognostic markers and putative therapeutic targets for hepatocellular carcinoma. Mol Aspects Med 2010, 31:179-193.

7. Colombino M, Sperlongano P, Izzo F, Tatangelo F, Botti G, Lombardi A, Accardo M, Tarantino L, Sordelli I, Agresti M, et al: BRAF and PIK3CA genes are somatically mutated in hepatocellular carcinoma among patients from South Italy. Cell Death Dis 2012, 3:e259.

8. Hassan MI, Waheed A, Yadav S, Singh TP, Ahmad F: Zinc alpha 2glycoprotein: a multidisciplinary protein. Mol Cancer Res 2008, 6:892-906

9. Zorin NA, Zorina VN, Zorina RM: Role of proteins of the macroglobulin family in regulation of tumor growth. Ontogenez 2006, 37:12-19.

10. Zorin NA, Zorina VN, Zorina RM: The role of macroglobulin family proteins in the regulation of inflammation. Biomed Khim 2006, 52:229-238.

11. Tada T, Ohkubo I, Niwa M, Sasaki M, Tateyama H, Eimoto T: Immunohistochemical localization of $\mathrm{Zn}$-alpha 2-glycoprotein in normal human tissues. J Histochem Cytochem 1991, 39:1221-1226.

12. He N, Brysk H, Tyring SK, Ohkubo I, Brysk MM: Zinc-alpha(2)-glycoprotein hinders cell proliferation and reduces cdc2 expression. J Cell Biochem Supp/ 2001, 36(Suppl):162-169.

13. Kong B, Michalski CW, Hong X, Valkovskaya N, Rieder S, Abiatari I, Streit S, Erkan $M$, Esposito I, Friess $H$, Kleeff J: AZGP1 is a tumor suppressor in pancreatic cancer inducing mesenchymal-to-epithelial transdifferentiation by inhibiting TGF-beta-mediated ERK signaling. Oncogene 2010, 29:5146-5158.

14. Albertus DL, Seder CW, Chen G, Wang X, Hartojo W, Lin L, Silvers A, Thomas DG, Giordano TJ, Chang AC, et al: AZGP1 autoantibody predicts survival and histone deacetylase inhibitors increase expression in lung adenocarcinoma. J Thorac Oncol 2008, 3:1236-1244.

15. Diez-Itza I, Sanchez LM, Allende MT, Vizoso F, Ruibal A, Lopez-Otin C: Znalpha 2-glycoprotein levels in breast cancer cytosols and correlation with clinical, histological and biochemical parameters. Eur J Cancer 1993, 29A:1256-1260.

16. Hale LP, Price DT, Sanchez LM, Demark-Wahnefried W, Madden JF: Zinc alpha-2-glycoprotein is expressed by malignant prostatic epithelium and may serve as a potential serum marker for prostate cancer. Clin Cancer Res 2001, 7:846-853.

17. Brysk MM, Lei G, Adler-Storthz K, Chen Z, Brysk H, Tyring SK, Arany I: Zincalpha2-glycoprotein expression as a marker of differentiation in human oral tumors. Cancer Lett 1999, 137:117-120.

18. Henshall SM, Horvath LG, Quinn DI, Eggleton SA, Grygiel JJ, Stricker PD, Biankin AV, Kench JG, Sutherland RL: Zinc-alpha2-glycoprotein expression as a predictor of metastatic prostate cancer following radical prostatectomy. J Natl Cancer Inst 2006, 98:1420-1424.

19. Lapointe J, Li C, Higgins JP, van de Rijn M, Bair E, Montgomery K, Ferrari M, Egevad L, Rayford W, Bergerheim U, et al: Gene expression profiling identifies clinically relevant subtypes of prostate cancer. Proc Natl Acad Sci U S A 2004, 101:811-816.

20. Gao Q, Qiu SJ, Fan J, Zhou J, Wang XY, Xiao YS, Xu Y, Li YW, Tang ZY: Intratumoral balance of regulatory and cytotoxic $T$ cells is associated with prognosis of hepatocellular carcinoma after resection. J Clin Oncol 2007, 25:2586-2593.

21. Sobin LH, Fleming ID: TNM Classification of Malignant Tumors, fifth edition (1997). Union Internationale Contre le Cancer and the American Joint Committee on Cancer. Cancer 1997, 80:1803-1804.

22. Kononen J, Bubendorf $L$, Kallioniemi A, Barlund M, Schraml P, Leighton S, Torhorst J, Mihatsch MJ, Sauter G, Kallioniemi OP: Tissue microarrays for 
high-throughput molecular profiling of tumor specimens. Nat Med 1998, 4:844-847.

23. Soslow RA, Dannenberg AJ, Rush D, Woerner BM, Khan KN, Masferrer J, Koki AT: COX-2 is expressed in human pulmonary, colonic, and mammary tumors. Cancer 2000, 89:2637-2645.

24. Li M, Luo RZ, Chen JW, Cao Y, Lu JB, He JH, Wu QL, Cai MY: High expression of transcriptional coactivator p300 correlates with aggressive features and poor prognosis of hepatocellular carcinoma. J Trans/ Med 2011, 9:5.

25. Irmak S, Tilki D, Heukeshoven J, Oliveira-Ferrer L, Friedrich M, Huland H, Ergun S: Stage-dependent increase of orosomucoid and zinc-alpha2glycoprotein in urinary bladder cancer. Proteomics 2005, 5:4296-4304.

26. Abdul-Rahman PS, Lim BK, Hashim OH: Expression of high-abundance proteins in sera of patients with endometrial and cervical cancers: analysis using 2-DE with silver staining and lectin detection methods. Electrophoresis 2007, 28:1989-1996.

27. Lei G, Arany I, Selvanayagam P, Rajaraman S, Ram S, Brysk H, Tyring SK, Brysk MM: Detection and cloning of epidermal zinc-alpha 2-glycoprotein CDNA and expression in normal human skin and in tumors. J Cell Biochem 1997, 67:216-222.

28. Mazoujian G: Apocrine carcinoma of the breast. Am J Clin Pathol 1990, 94:485-486.

29. Descazeaud A, de la Taille A, Allory Y, Faucon H, Salomon L, Bismar T, Kim R, Hofer MD, Chopin D, Abbou CC, Rubin MA: Characterization of ZAG protein expression in prostate cancer using a semi-automated microscope system. Prostate 2006, 66:1037-1043.

30. Gagnon S, Tetu B, Dube JY, Tremblay RR: Expression of Zn-alpha 2glycoprotein and PSP-94 in prostatic adenocarcinoma. An immunohistochemical study of 88 cases. Am J Pathol 1990, 136:1147-1152.

31. Dubois V, Delort L, Mishellany F, Jarde T, Billard H, Lequeux C, Damour O, Penault-Llorca F, Vasson MP, Caldefie-Chezet F: Zinc-alpha2-glycoprotein: a new biomarker of breast cancer? Anticancer Res 2010, 30:2919-2925.

32. Bing C, Bao Y, Jenkins J, Sanders P, Manieri M, Cinti S, Tisdale MJ, Trayhurn $P$ : Zinc-alpha2-glycoprotein, a lipid mobilizing factor, is expressed in adipocytes and is up-regulated in mice with cancer cachexia. Proc Natl Acad Sci U S A 2004, 101:2500-2505.

33. Russell ST, Tisdale MJ: Effect of eicosapentaenoic acid (EPA) on expression of a lipid mobilizing factor in adipose tissue in cancer cachexia. Prostaglandins Leukot Essent Fatty Acids 2005, 72:409-414.

34. Lapointe J, Malhotra S, Higgins JP, Bair E, Thompson M, Salari K, Giacomini CP, Ferrari M, Montgomery K, Tibshirani R, et al: hCAP-D3 expression marks a prostate cancer subtype with favorable clinical behavior and androgen signaling signature. Am J Surg Pathol 2008, 32:205-209.

doi:10.1186/1479-5876-10-106

Cite this article as: Huang et al: Decreased expression of zinc-alpha2glycoprotein in hepatocellular carcinoma associates with poor prognosis. Journal of Translational Medicine 2012 10:106.

\section{Submit your next manuscript to BioMed Central and take full advantage of:}

- Convenient online submission

- Thorough peer review

- No space constraints or color figure charges

- Immediate publication on acceptance

- Inclusion in PubMed, CAS, Scopus and Google Scholar

- Research which is freely available for redistribution

Submit your manuscript at www.biomedcentral.com/submit
C Biomed Central 